\title{
Saúde e segurança no trabalho em unidades armazenadoras de grãos no Estado do Mato Grosso do Sul $^{1}$
}

\section{Health and safety in grain handling at the Mato Grosso do Sul State}

DOI

10.30612/re-ufgd.v6i12.10462

Vanderleia Schoeninger $^{2}$
Valdiney Cambuy Siqueira ${ }^{2}$
André Niciporenco Neto $^{3}$
Rafael Araujo Leite ${ }^{3}$
Vinicius Duarte Pinto $^{3}$
Lucas Rodrigues Ferraz

Recebido em $30 / 09 / 2019 \quad$ Aceito em : $13 / 11 / 2019$

Resumo: O trabalho em unidades que recebem, processam e armazenam produtos agrícolas na forma de grãos e sementes é de alto risco para os operadores, visto que muitos destes desconhecem a gravidade dos problemas que podem vir a acontecer nestes ambientes. Dessa forma, objetivou-se com a realização deste trabalho apresentar experiencias com a realização de dois projetos de extensão universitária, que tinham como foco principal a difusão de informações e expansão da cultura de segurança em atividades de trabalho, na área de armazenagem de produtos agrícolas. $\mathrm{O}$ primeiro projeto foi realizado com o intuito de promover discussões acerca da saúde dos trabalhadores e orientação de segurança a operadores da Unidade Armazenadora Copasul, do munícipio de Deodápolis-MS. Para tal a equipe executora das ações de extensão produziu materiais didáticos como folders, banners, apresentações, compilado de vídeos, e todos foram usados em atividade de palestra realizada pela equipe, com alunos do curso de Engenharia Agrícola e Agronomia, da Universidade Federal da Grande Dourados. Também foi elaborado e construído pela equipe um protótipo de silo, ferramenta didática usada em simulações de acidentes como soterramento e engolgamento. No segundo projeto foi elaborado questionário estruturado para o levantamento de informações sobre o conhecimento do assunto junto aos colaboradores de unidades armazenadoras do Estado do MS. Após a aplicação dos questionários, via online, os dados obtidos foram avaliados e discutidos juntamente com a equipe e serão importantes para outras atuações e difusão do tema. A realização de ambas os projetos de extensão foram de grande valia para a equipe executora e o grupo pretende prosseguir com atividades futuras na área com vistas para a expansão da cultura de conscientização e prevenção de acidentes nos trabalhos agrícolas.

Palavras chave: Acidentes em silos. Espaços confinados. Engolfamento.

\footnotetext{
1 Este artigo relata as experiências obtidas com a realização de dois projetos de extensão praticados no âmbito da Universidade Federal da Grande Dourados aprovados via editais específicos: Edital PROEX/PIBEX No 12 -

Projetos, cursos e eventos de extensão com ônus para a UFGD (2015) e Edital PROEX/PIBEX/PIVEX N³9/2017 -

Ações de Extensão da UFGD (Com ônus para UFGD) (2017);

${ }^{2}$ Docente da Faculdade de Ciências Agrárias, Universidade Federal da Grande Dourados, UFGD,

vschoeninger@ufgd.edu.br;

${ }^{3}$ Discente do curso de graduação em Engenharia Agrícola, UFGD;

${ }^{4}$ Discente do curso de graduação em Agronomia, UFGD;

${ }^{5}$ Engenheira Agrícola.
} 
Abstract: The labor in grain handling that receive, process and store agricultural products in the form of grains and seeds is a high risk for operators, as many of them are unaware of the seriousness of the accident that may occur in these environments. The objective of this paper was to present experiences with the accomplishment of two university extension projects, which had as main focus the dissemination of information and expansion of safety culture in work activities, in the area of grain handling. The first project was carried out in order to promote discussions about workers' health and safety guidance to operators of the Copasul Storage Unit, in the Deodápolis-MS city. The extension action team produced teaching materials such as brochures, banners, presentations, compiled videos and these were used in a lecture by the team, with students from the Agricultural Engineering and Agronomy courses, from the Federal University of Grande Dourados. A bin prototype was projected and built by the team and is a didactic tool used in accident simulations such as engulfment and grain entrapment. For the second project a structured investigation was prepared to collect informations about the subject's knowledge from the workes of storage units in the Mato Grosso do Sul State. After the online applying data were evaluated and discussed with the team and will be important for other actions and dissemination of the subject. The accomplishment of both extension projects were of great signficance to the team and this group intends to continue with future activities in the area with a view to expanding the culture of awareness and prevention of agricultural accidents.

Key words: Grain bins accidents. Confined spaces. Grain entrapment.

\section{Introdução}

A armazenagem de grãos é um processo fundamental no setor agrícola que garante estoques para o abastecimento dos mercados interno e externo. Weber (2005) define o armazenamento como uma técnica que tem por objetivo manter os grãos estocados e em excelente estado de conservação. Porém, tal operação não deve ser compreendida apenas como a simples guarda do produto em armazéns. Todas as operações unitárias como a recepção, amostragem, descarga, transporte mecânico, pré-limpeza e limpeza, secagem, limpeza e manutenção de equipamentos, devem ser consideradas no processo de armazenagem como um todo (MILMAN, 2002).

A execução das atividades citadas pode trazer inúmeros riscos à saúde e segurança dos envolvidos nos processos de armazenamento. Estes riscos se dão devido primeiramente ao fato de que muitos locais em uma unidade de armazenamento de grãos serem considerados espaços confinados e exigem muita cautela na execução de atividades. Espaços confinados não são projetados para a ocupação humana por não apresentarem ventilação suficiente, locais nos quais poderá ocorrer presença de gases altamente tóxicos (BRASIL, 2019). Dessa forma, durante realização de atividades rotineiras em unidades de armazenamento, existem elevados riscos devido a estas e outras condições de riscos (GOUVEIA et al, 2013; GUASQUES et al, 2018). As 
atividades realizadas em complexos estruturais de armazenagem são de extrema importância e exigem ações de profissionais bem preparados para que o objetivo de plena manutenção e preservação de grãos seja alcançado.

Devido ao processo respiratório dos grãos armazenados são verificadas a formação de gás carbônico, água e energia na forma de calor. A intensidade da respiração na massa armazenada é influenciada pelas condições do meio como temperatura, umidade relativa, presença de insetos e microorganismos como fungos. Em condições inapropriadas pode ocorrer deterioração do material vegetal e dessa forma observa-se a formação de demais gases tóxicos como sulfeto de hidrogênio. Outro gás de extrema importância é o metano liberado por microorganismos, como bactérias metanogênicas, que pode causar explosões no meio (SILVA, 2005).

A deterioração da massa de grãos armazenada é resultado da interação entre variáveis físicas, que são temperatura, umidade e propriedades físicas dos grãos, variáveis químicas da massa de grãos como a disponibilidade de oxigênio no ar intergranular, variáveis biológicas de fontes internas como a longevidade, respiração, maturidade pós-colheita e germinação. Além disso, destaca-se também as variáveis biológicas de fontes externas como os fungos, leveduras, bactérias, insetos, ácaros, roedores e pássaros que podem estar presentes no meio de armazenagem (FARONI et al., 2009; HERRMANN et al., 2009). Dessa forma poderão ocorrer elevadas concentrações de dióxido de carbono $\left(\mathrm{CO}_{2}\right)$, metano $\left(\mathrm{CH}_{4}\right)$, sulfeto de hidrogênio $\left(\mathrm{H}_{2} \mathrm{~S}\right)$ presentes no meio e considerados irritantes e asfixiantes (SILVA, 2005), além de explosivos.

Outro risco dos ambientes de armazenagem se dá devido a presença de poeiras. Estas poeiras normalmente ocorrem em pontos de instalações onde há descarga de grãos, moagem, descarga, movimentação, transporte etc., e não havendo a correta exaustão, poderão desencadear incêndios e explosões (ZAGO, 2013). Além disso, estes materiais particulados em suspensão são carreadores de substâncias alergênicas que poderão causar infecções na pele e no sistema respiratório dos colaboradores.

Acidentes em que ocorre o engolfamento e soterramento do funcionário na massa de grãos armazenados também são comuns e muitas vezes deixam vítimas fatais e podem ocorrer por exemplo quando os operadores caminham sobre a massa de grãos e o sistema de descarga do silo é acionado. Outra situação do engolfamento ocorre quando abaixo de uma camada de grãos ocorrem estruturas com espaços vazios ou ocos, então o operador ao caminhar sob o topo do armazém acaba caindo nestes espaços e imediatamente são afundados e soterrados pela ação mecânica da massa de grãos. Em países como os Estados Unidos, o início da preocupação com problemas como o 
engolfamento e soterramento em silos armazenadores data dos anos 70 com o levantamento de dados do número de vítimas deste tipo de acidente e a partir destes, ações foram promovidas visando ampliar a conscientização sobre estes acidentes entre fazendeiros e envolvidos no setor (RIEDEL; FIELD, 2011). Issa et al (2014) apresenta o levantamento dos acidentes ocorridos em espaços confinados agrícolas e registrados nos Estados Unidos e apenas no ano de 2014 verificou-se que naquele país dos 70 casos relatados, 54\% foram engolfamentos em estruturas de armazenamento de grãos.

No Brasil, ainda não existe um levantamento oficial de informações que aborde estes acidentes em específico, porém sabe-se que ocorrem especialmente com aqueles operadores que desconhecem ou minimizam os riscos. Em 2018, apenas uma reportagem da British Broadcasting Corporation apresentou e discutiu números levantados em noticiários sobre o tema. A reportagem demostrou que entre os anos de 2009 e 2018 no país, 106 pessoas morreram em silos de grãos (FELLET, 2018), e que os estados brasileiros responsáveis pelos maiores índices de capacidade estática também apresentam o maior número de acidentes.

Dessa forma, ações de expansão da cultura de segurança com o máximo de difusão de informações sobre os riscos existentes nestes ambientes são de extrema importância, pois contribuem para ampliar o conhecimento daqueles que trabalham direta e indiretamente com o setor de armazenagem. Logo este artigo visa apresentar as experiencias e resultados com a realização dos dois projetos de extensão universitária que tinham como objetivo principal a difusão de informações e expansão da cultura de segurança em atividades de trabalho em na área de armazenagem de produtos agrícolas.

\section{Materiais e Métodos}

Esse trabalho apresenta as atividades de extensão desenvolvidas pela equipe executora e que foram submetidas e aprovadas pelos editais PROEX/PIBEX n ${ }^{\circ} 12$ - Projetos, cursos e eventos de extensão com ônus para a UFGD no ano de 2015 e Edital PROEX/PIBEX/PIVEX n ${ }^{\circ}$ 39/2017 - Ações de Extensão da UFGD (Com ônus para UFGD) do ano de 2017.

O primeiro projeto foi realizado com o intuito de promover as discussões sobre o tema e tinha como título "Levantamento dos fatores que interferem na qualidade dos grãos e saúde dos trabalhadores e orientação de segurança aos operadores da Unidade Armazenadora Copasul Dourados". A ênfase foi direcionada para a orientação dos operadores, não realizando-se o levantamento de fatores de risco nas estruturas que poderiam afetar a saúde do colaborador, assim 
como a qualidade do produto armazenado nas estruturas.

A equipe executora das ações de extensão desenvolveu ao longo do projeto, materiais didáticos como folders, banners, apresentações, compilado de vídeos, usados em atividade de palestra pelos alunos do curso de Engenharia Agrícola. Também foi elaborado e construído um protótipo de silo, usado em simulações de acidentes como soterramento e engolgamento na massa de grãos. O público alvo das ações de extensão deste primeiro projeto compreendeu os funcionários da unidade armazenadora, alunos de graduação em Engenharia Agrícola e outros profissionais da área de armazenagem, totalizando-se 66 participantes.

O segundo edital abordou a realização e levantamento de informações relativas aos conhecimentos de colaboradores sobre as condições de saúde e segurança no trabalho em unidades de armazenamento de grãos da região sul do estado através da aplicação de questionário. Dessa forma realizou-se as etapas de estudos, construção e elaboração do questionário estruturado e o mesmo foi difundido entre trabalhadores da área de armazenamento e processamento de produtos agrícolas no Estado do Mato Grosso do Sul. A forma de divulgação e aquisição dos dados foi utilizando a ferramenta de formulário Google Forms. O público alvo compreendeu 36 participantes que responderam o questionário e a equipe contou com a parceria de 14 participantes, entre eles alunos de graduação, professores e alunos de pós-graduação. Os resultados foram apresentados na forma de porcentagem.

\section{Resultados e Discussão}

Durante o primeiro projeto de extensão trabalhou-se no desenvolvimento de alguns materiais que contribuíram no suporte das ações de conscientização. Estes materiais compreenderam banners, panfletos e a construção de um protótipo de silo para representação de acidentes. Os banners abordaram os assuntos Norma regulamentadora (NR) 33 (BRASIL, 2019), riscos e medidas preventivas para trabalhos em espaços confinados, os gases presentes em unidades de processamento de produtos agrícolas e seus riscos para o trabalhador e por fim o uso correto dos equipamentos de segurança. Os folders abordaram a temática em torno de equipamentos individuais e coletivos de segurança que são utilizados nas estruturas de armazenagem de grãos, tratando sobre a importância, cuidado, manutenção e substituição destes equipamentos. Para a produção deste material gráfico produzido foram realizadas reuniões com a equipe executora, nas quais discutiamse questões bibliográficas e de design.

O protótipo de silo foi um produto do projeto de extensão e foi usado como objetivo 
descrever situações de risco para os trabalhadores que realizarão atividades dentro das estruturas. Dentre essas situações, uma das mais graves em unidades de processamento e armazemanento de produtos agrícolas é o engolfamento (Figura 1). Este tipo de acidente pode acontecer quando há algum operador sob o topo da camada de grãos e o sistema de descarga do silo é ligado. Também pode ocorrer quando embaixo de uma camada formada por grãos, forma-se um espaço oco ou vazio (devido à problemas no enchimento da estrutura e acomodação dos grãos) e então o trabalhador durante atividades de inspeção ( como por exemplo a realização de limpeza e desobstrução; regulagem de sensores de temperatura dos silos; acomodação de estruturas de vedação para processos de expurgo) pode vir a cair nestes espaços e vem a ficar soterrado por quilos ou toneladas de grãos que se moverão para ocupar aquele espaço vazio. No engolfamento a vítima pode dentro ser soterrada em poucos segundos, sendo de grande dificuldade os procedimentos de salvamento.
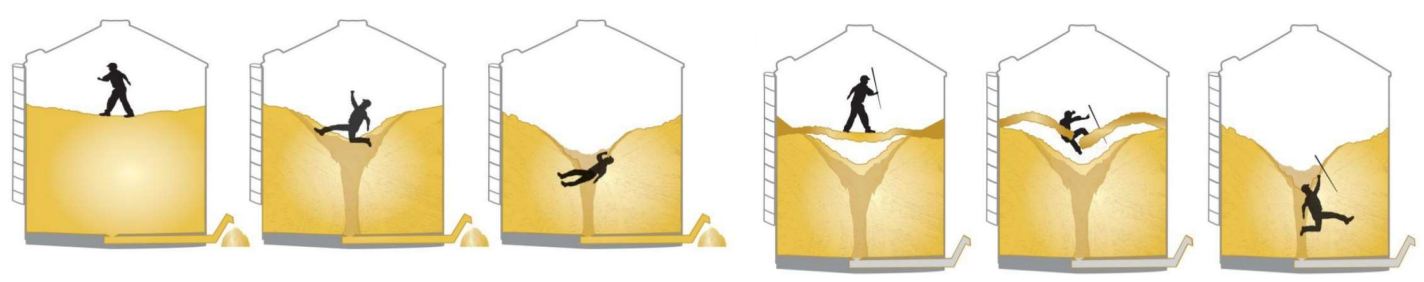

Figura 1. Situações em silos que podem ocorrer acidentes de engolfamento e sufocamento nas unidades de armazenamento e processamento de produtos agrícolas. Fonte: GHSC (2019).

Foi então desenvolvido e construído um silo com corpo cilíndrico de $50 \mathrm{~cm}$ de altura e diâmetro de $35 \mathrm{~cm}$ totalizando um volume de 48 L, com um "chapéu” de 10 centímetros de altura e um ângulo de $29^{\circ}$, e tremonha de descarga em ângulo de $45^{\circ}$ com volume de $16 \mathrm{~L}$ e orifício de 4 $\mathrm{cm}$ de diâmetro e válvula de descarga que regula a vazão (Figura 2 - b). A estrutura cilíndrica e tremonha foram dispostas em um suporte de $70 \mathrm{~cm}$ altura; totalizando uma altura total é de 1,30 metros. O material utilizado para a confecção da tremonha e chapéu foi aço galvanizado; para a parede do cilindro foi utilizada uma tela de arame galvanizado com malha de $50 \mathrm{~mm}$ que foi usada como suporte para uma chapa de acrílico moldada. O uso do material acrílico foi importante visto que permite uma melhor visualização do processo de movimentação do produto no silo e como poderiam ocorrer determinados acidentes em pequena escala. 


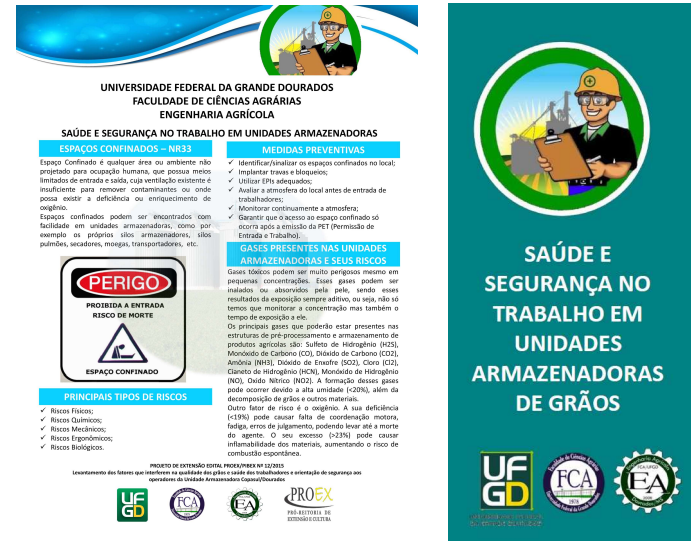

$\bullet$

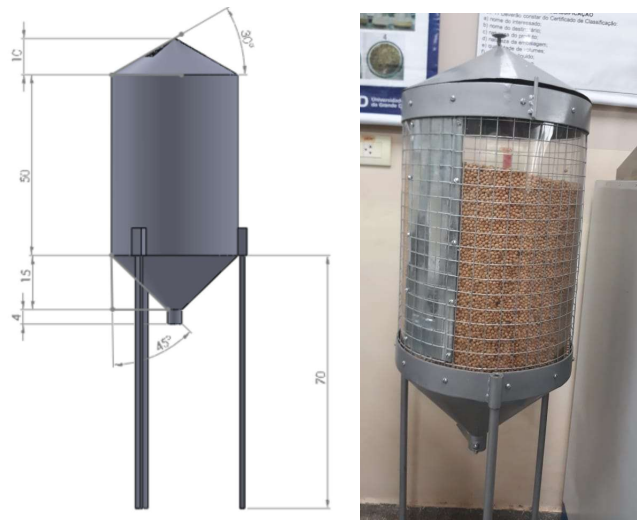

(b)

Figura 2. Confecção de material didático para atividades de conscientização, banner e capa de folder (a) e mini silo usado em representação de acidentes nas unidades de armazenamento e processamento de produtos agrícolas (b).

De posse dos materiais foi então realizado um seminário de capacitação de colaboradores na unidade armazenadora de grãos da Copasul, filial Deodápolis no Mato Grosso do Sul. A atividade foi intitulada "Saúde e Segurança no Trabalho em Unidades Armazenadoras", com 4 horas de duração e contou com a presença de 16 participantes. Foi realizada primeiramente uma exposição pelos alunos do projeto sobre os temas aprofundados no decorrer do projeto, apresentaram-se os materiais de apoio (banners, folders e mini silo simulador de acidentes) e por fim foi promovida discussão sobre o assunto com troca de experiências pela equipe operacional da empresa orientações dos acadêmicos participantes do projeto. Essa atividade foi apontada como de grande valia pelos colaboradores da empresa que puderam atualizar e aprimorar seus conhecimentos sobre a importância da manutenção das condições de saúde e segurança nos ambientes de trabalho que compreende especialmente unidades de processamento e armazenamento de grãos.

Para os acadêmicos de graduação que participaram das atividades também foi uma experiência de imersão às futuras demandas profissionais, que envolvem preparo de materiais, estudos e orientação aprofundada, apresentação ao público, gestão de conflitos entre equipes, entre outros. Esses acadêmicos tiveram a oportunidade de presenciar a problemática e a prática ligadas às questões de saúde e segurança no trabalho. Atualmente os materiais oriundos desse projeto são usados como recurso didático em aulas práticas de disciplinas profissionalizantes dos cursos de Agronomia e Engenharia Agrícola da UFGD, que abordam o tema em seus planos de ensino. A maquete mencionada também foi empregada em feiras e demonstrações dos alunos à sociedade, contribuindo ainda mais para a difusão da cultura de conhecimento e prevenção de acidentes em 
unidades de armazenagem de grãos.

O segundo projeto englobou um embasamento muito importante proveniente das experiências do projeto anterior. Neste projeto ocorreu suporte financeiro na forma de bolsa de extensão para um acadêmico da Universidade e o mesmo junto com a equipe foi o responsável pela execução das atividades. Após estudos e discussões iniciais, a equipe elaborou um questionário estruturado e o mesmo foi adicionado à plataforma Google forms. Este questionário foi divulgado por e-mail e via redes sociais (grupos com trabalhadores do setor). Apesar do intuito de se fazer o questionário totalmente online para que alcançasse a maior parte do Estado e a maior quantidade de participantes, não obtivemos um bom resultado. Durante quatro meses realizou-se divulgação, porém obtivemos apenas respostas de 36 participantes. Muitas vezes era necessário entrar em contato via ligação telefônica com as empresas e tratar diretamente com os responsáveis pelo setor para solicitar aos seus colaboradores que acessassem o questionário e respondessem. Muitos nos diziam que prefeririam responder usando um questionário impresso e não no celular ou computador. Essa é uma observação importante, pois muitas vezes a acessibilidade não implica em condições favoráveis à coleta de dados. Porém, com base nos resultados obtidos o perfil dos participantes era $73,5 \%$ do gênero masculino e o restante feminino; a faixa etária prioritária era entre 26 e 40 anos $(64,7 \%)$ e cerca de $17,6 \%$ entre 16 e 25 anos e o restante entre 41 e 50 anos. Entre as atividades e profissões dos participantes identificou-se classificador de grãos, operador de máquinas de limpeza ou secador, gerente operacional, setor administrativo, mecânico, operador de balança rodoviária, engenheiro, proprietário de armazém, técnico em saúde e segurança no trabalho, gestor de obras e contador. Os entrevistados eram provenientes dos municípios de Dourados (28\%), Naviraí (18\%), Caarapó, Campo Grande e Maracaju (11\% cada); e por fim Deodápolis, Itaporã, Jardim, Laguna Carapã, Nova Andradina, Rio Brilhante e Ponta Porã (todos com 3 \% dos participantes).

Todos os participantes mostraram bom conhecimento no que tange espaços confinados definindo-os como lugares impróprios para ocupação humana onde pode haver insuficiência de oxigênio; e 94\% sabem da ocorrência de espaços confinados em estruturas armazenadoras de grãos. Todos os entrevistados também sabem o que é EPI (equipamento de proteção individual) e sua importância do uso correto. Um total de $91 \%$ dos participantes sabe da existência de lugares onde pode haver a existência de gases tóxicos formados por processos de deterioração do produto e 94\% afirmaram que sabem do perigo de explosões devido aos gases e poeiras produzidos no local. Também puderam identificar os principais sintomas causados ao se ter contato com os gases tóxicos como gás sulfídrico e o metano que podem ser liberados em processos 
de decomposição de grãos, apontando-se como principais a perda de consciência, dor de cabeça, náuseas e fadiga durante a exposição. Esses resultados foram muito positivos, visto que mostraram que os trabalhadores participantes da entrevista mostraram amplo conhecimento sobre os temas abordados.

Quando perguntados sobre o uso do detector de gases portátil durante as atividades realizadas em locais como poço de elevador, silos e túneis, $60 \%$ afirmaram que realizam o uso do EPI, já 14,3\% não utilizam (Figura 3 -a). Dentre os acidentes e situações consideradas mais perigosas entre os participantes destacaram-se o engolfamento seguido do soterramento (90\%) e quedas durante trabalhos em altura (80\%). Cerca de $83 \%$ dos participantes afirmaram que já fizeram treinamentos na área de saúde e segurança no trabalho. Sobre as situações de engolfamento e soterramento, $57,1 \%$ dos participantes responderam que já realizaram algum tipo de atividade de treinamento com foco nesse tipo de acidente (Figura $3-b$ ). Nenhum dos participantes da pesquisa disse ter sofrido algum acidente de trabalho, mais um deles disse já ter presenciado a explosão de um túnel em um armazém, porém sem nenhuma vítima. Também foi verificado que $68,9 \%$ dos participantes já haviam realizado algum treinamento com o tema segurança do trabalho em espaços confinados, tratando especialmente a norma regulamentadora número 33.
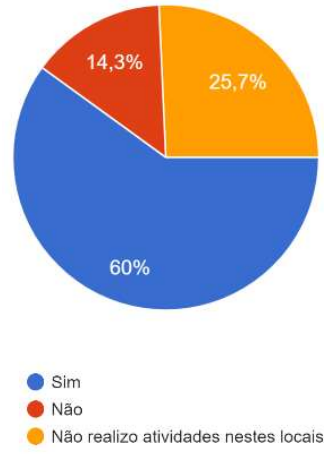

(a)

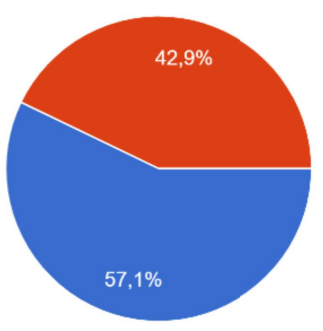

$\operatorname{Sim}$ Não

(b)

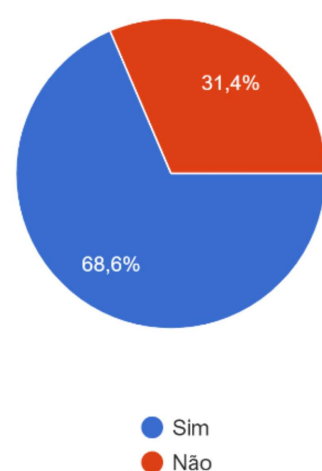

(c)

Figura 3. Resultados da pesquisa realizada com trabalhadores da área de armazenagem de grãos no Estado do Mato Grosso do Sul, (a) dispõe a porcentagem de usuários do detector de gases portátil durante atividades em espaços confinados; (b) porcentagem de trabalhadores que já realizaram algum tipo de atividade de treinamento em resgate de acidentes como o engolfamento e (c) porcentagem de trabalhadores que já realizaram treinamentos sobre a norma regulamentadora número 33.

\section{Conclusão}

Concluiu-se que as ações que promoveram a expansão da cultura de conscientização 


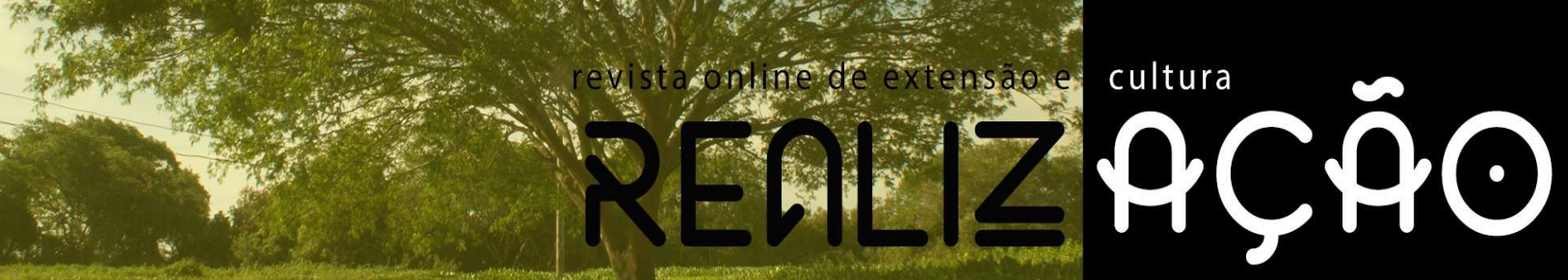

dos riscos e comportamento seguro nas unidades armazenadoras agrícolas são de extrema importância, pois a ocorrência de acidentes em unidades armazenadores ainda é frequente no país. A atuação nos dois projetos de extensão foi de grande valia para a equipe executora e pretende-se prosseguir com atividades futuras na área com vistas para a expansão da cultura de conscientização e prevenção de acidentes nos trabalhos agrícolas.

\section{Agradecimentos}

À Pró-Reitoria de Extensão e Cultura da Universidade Federal da Grande Dourados, pelo financiamento e bolsas dos projetos. À cooperativa Copasul pela parceria e a todos os trabalhadores do setor que colaboraram com a participação no questionário.

\section{Referências}

BRASIL. Ministério do trabalho. Portaria MTE $n^{0}$ 1.409, Norma Regulamentadora 33 segurança e saúde nos trabalhos em espaços confinados. http://www.guiatrabalhista.com.br/legislacao/nr/nr 33 .htm, acesso em 30 de junho de 2019.

FARONI L. R. D. Fatores que influenciam a qualidade dos grãos armazenados. Universidade Federal de Viçosa, p. 1-15. 1998. Disponível em: ftp.ufv.br/dea/Disciplinas/Leda/ENG370/Fatores \%20influenc\%20qualid\%20graos.doc. Acesso em: 10 jul. 2017.

FELLET, J. As silenciosas mortes de brasileiros soterrados em armazéns de grãos. Artigo de jornal. Disponível em: https://www.bbc.com/portuguese/brasil-45213579

GASQUES; A. C. F.; SANTOS, J. D.; CASTRO, T. R.; FERREIRA, T. S. Análise do ruído ocupacional: estudo de caso em uma casa de máquinas de uma unidade armazenadora de cereais. Revista Produção Industrial \& Serviços, v.5, n.2, p. 13-24, 2018.

GOUVEIA, R. G. L.; GALVANI, E. A. S.; HENRIQUE JUNIOR, M.; GOUVEIA, R. G.L. Avaliação das condições de segurança no trabalho em armazéns agrícolas na cidade de Tangará da Serra/MT-Brasil. Espacios, v.34, n. 10, p. 1-7, 2013.

Grain Handling Safety Coalition. Material de apoio para conscientização, 2019. Disponível em: https:/grainsafety.org/wp-content/uploads/2016/05/Handout-GRAIN-BIN-ENTRY-HAZARDSCOLOR-Rev-9 15-PDF.pdf acesso em 25/09/2019

HERRMANN, D. R.; CARVALHO, M. J. DE; ZACHOW, K.; SCHOLZ, F.; RABBERS, D.; TSUTSUMI, C. Y.; ZONIN, W. Avaliação da resistência de cultivares de milho ao ataque de Sitophilus sp. em grãos armazenados. Revista Brasileira de Agroecologia, v. 4, n. 1, p. 4290-4293, 2009.

MILMAN, Mário José. Equipamentos para pré-processamento de grãos. Pelotas: Universitária - 
